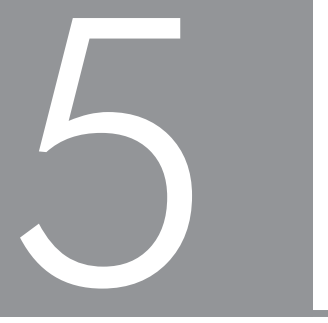

\title{
AN EXAMPLE OF CRITICAL CITIZENSHIP EDUCATION IN AN ARTS CURRICULUM
}

\section{INTRODUCTION}

If one considers the importance of global and local change and transformation for constructing just, sustainable and peaceful societies globally, initiatives such as the United Nations Millennium Development Goals (Kindzeka 2014) and The Earth Charter Initiative (2012) feature prominently. As discussed earlier, the need for such kind of transformation in thought and action in South Africa as an evolving democracy is vital, as underlined by several policy initiatives, both in higher education institutions and at a national level (DHET 2014; DoE 1997; NPC 2011).

At Stellenbosch University (SU), where we both work as academics, the HOPE Project (see Botman 2011 for details on this initiative) was launched in 2008. Its aim was and still is to find concrete ways to reflect on historical influences on the current South African society and to address the need for change towards a higher education that significantly contributes to society. To correspond with this stated aim, a module called "Critical Citizenship" was introduced for first- to third-year Visual Communication Design students at the Department of Visual Arts at SU. The case study in critical citizenship that we elaborate on involves the Critical Citizenship module in particular. The case study had as its aim to explore the perceptions and attitudes of students, a group of learners from a township school and two art lecturers who participated in the Critical Citizenship module regarding personal transformation through teaching and learning in the module. As a framework for the study, the importance of considering the emotional dimensions of learning (also see Chapters 3 and 4) was emphasised, thereby implying that students should be understood and treated as thinking, feeling and acting persons. The project had two clear objectives: firstly, to identify emotional reactions to the Critical Citizenship module and secondly, to 
establish what these reactions revealed about the immediate and broader contexts of the teaching and learning spaces in which university students, school learners and lecturers learn and teach.

Case study details are presented under the following headings: the research context, research process and research results.

\section{RESEARCH CONTEXT}

Given the socially constructed nature of the concepts underlying the general notion of critical citizenship (e.g. tolerance, human rights, social justice, social reconstruction and democracy), it is clear that, when considering the Critical Citizenship module that was initiated by the Department of Visual Arts at SU, one cannot approach it as an isolated case, as university education is situated within a range of historical and socio-political factors and contexts (Cohen et al. 2007; Stake 1995; Teichler 2005; Zembylas 2007c). We have referred to such factors and contexts in some detail in the previous chapters. This corresponds with the view adopted by Giroux (1985:xxiv) in his introduction to Freire's book, The politics of education: Culture, power and liberation (1985), where he remarked that "to understand the present, in both institutional and social terms, educators must place all educational context in a historical context, in order to see clearly their genesis and development".

In the SU case, such contexts include higher education within South Africa's colonial and apartheid histories, SU as a transforming institution and the Department of Visual Arts with its Visual Communication Design course as a critical citizenship education experiment. As we have dealt with the South African historical position earlier, we focus here on the institutional history of SU as well its Department of Visual Arts as an academic unit.

\section{Stellenbosch University}

SU has been, and is still, associated mostly with the language of Afrikaans and in various respects historically linked to National Party political domination between 1948 and the late 1980s. The institution was therefore also well associated with apartheid regime leaders. Political leaders from this era, such as Dr Hendrik F. Verwoerd and Dr D.F. Malan, studied and lectured on its campus. Although SU recently had, for the first time since the early parts of the previous century, a majority of first-year English-speaking students, overall, however, it still has a mostly white, Afrikaans lecturer and student population. For non-Afrikaans lecturers and students attending SU, these close political and cultural associations could still potentially 
influence perceptions and attitudes towards the institution. It may also subconsciously influence teaching and learning.

The SU mission statement outlines its aims to create an academic community that (a) investigates and innovatively implements appropriate and sustainable approaches to the development of Africa; (b) aligns its research with a wideranging spectrum of challenges facing the world, Africa, our country and the local community; (c) maintains student-centred and future-oriented learning and teaching that establish a passion for lifelong learning; (d) invests in the innovative scholarship and creative ability of all its people; (e) leverages the inherent power of diversity; and ( $f$ ) establishes and extends synergistic networks in which the university is a dynamic partner (SU 2012).

With regard to policies, institutional values and commitments, SU clearly takes social transformation seriously. The implementation of such policies, values and commitments for it to become real in classrooms, outside of classrooms and in everything students, lecturers and communities do, is however not a simple feat. Even though SU currently endorses critical thinking and a deconstruction of ideas, such changes most often still take place from the perspective of a traditional Western framework of knowledge production. It suggests that the legitimacy of the Western knowledge system as the norm is often not examined critically enough (also see Remenyi 2004). For the University's policies, values and commitments to be put into practice, a change of thinking and actions is required; that what is often ingrained in peoples' minds as "normal" should be questioned. What is therefore needed is the skill of critical self-awareness so to realise how actions might still be driven forth by previous dominant, ingrained discourses and ideologies. Such awareness is essential if one wants to translate what makes sense on a personal and institutional level, and put this into action - in this critical citizenship education case, it was tolerance, mutual respect, non-racialism and the redress of inequalities (SU 2013; 2012).

As part of the public South African higher education system, SU is inevitably situated within the country's post-apartheid and post-colonial context. Only looking at the apartheid context in our research would have given a partial view, because apartheid was a specific extension of colonial circumstances. One needs to realise, however, even though we refer here to a post-colonial and post-apartheid era, particular aspects of racial discrimination and "othering" are still present - not only at SU, but also at other South African universities (see HESA 2008). 


\section{The Visual Communication Design programme}

The Critical Citizenship module forms part of the Visual Communication Design programme at the Department of Visual Arts at SU. It has been designed so that student participants in the module may become aware of their potential to hold up the University's vision, values and commitments, and to take these further into curricula, teaching and learning. Such learning also serves as something to be personally explored, otherwise it may remain at a distance and can easily be ignored or brushed aside.

The last sentence of the vision statement of the Department of Visual Arts refers directly to the Department's commitment to citizenship education and social responsibility in the training of artists and designers:

Through an integrated approach to teaching, research and community interaction, we strive to inculcate in students self-reflection, commitment and respect for the diversity of South African culture. ${ }^{1}$

Since the Critical Citizenship module in question here forms part of the Visual Communication Design programme offered at the Department of Visual Arts, an impression of the field of design in general may be necessary to provide a further context for the case: Visual communication design involves what Buchanan (2001:9) describes as the human ability of imagining, intending, and producing artefacts that "serve human beings in the accomplishment of their individual and collective purposes". But apart from what Buchanan (2001) describes, there has been a pertinent focus on socially responsible design as an important part of visual communication design in many countries in the world. Parker (2011) refers to the use of different terms that encompass socially responsible design, namely "service design" in the USA, "transformation design" in the UK and "concept design" in Europe.

Frascara (2002:33) differentiates between various areas of practice in design, viz. "design that works to make life possible, to make life easier and make life better". With making life better he refers to the capacity to attain high degrees of consciousness in our lives and our acts. He continues by saying the purpose is to reach cultural compassion to build nations and interact positively with others.

Locally, Sauthoff (2004:35) has remarked that there has been considerable progress in South Africa regarding a "new design order", but that the real need is for an improved balance and incorporation of the economic and social scopes of design. She has also pointed out that critical introspection supported by rigorous research is necessary. In this respect, Sauthoff (2004) refers to the only academic design

1 http://sun025.sun.ac.za/portal/page/portal/Arts/Departments/visual-arts\#vision 
journal in South Africa, Image\&Text, first published at the University of Pretoria in 1992, which promotes a critical approach towards design. On this topic, Sutherland (2004:52) mentions the dismantling of apartheid and the changes that followed the democratic elections, observing that "[i]t represents a paradigm shift in which a separatist and isolationist view has been overthrown in favour of a policy that espouses an integrated and expansive worldview".

The First Things First manifesto 2000, an updated version of a 1964 version, demonstrates similar trends in design. It can be read as a reaction against the misuse of designers' talent for selling products instead of focusing on improving communication and being socially responsible (Eye Magazine 1999). An excerpt from the manifesto reads as follows:

We propose a reversal of priorities in favor of more useful, lasting and democratic forms of communication - a mind shift away from product marketing and toward the exploration and production of a new kind of meaning.

(Eye Magazine 1999)

In response to the First Things First manifesto 2000, Poynor (2009:177) remarked that, if responsible and thinking individuals have a "responsibility to withstand the proliferating technologies of persuasion, then the designer, as a skilled professional manipulator of those technologies, carries a double responsibility". Poynor (2009:179) also encourages designers to aspire to a different future by motivating them, even in this late stage and in a "culture of rampant commodification, with all its blind spots, distortions, pressures, obsessions, and craziness", to find alternative ways of operating.

In describing the general context of design above, the focus has been specifically on socially responsible design and design activism, as this is also the case in the Visual Communication Design course at the Department of Visual Arts at SU. The Visual Communication Design course at SU focuses on the social responsibility of the student and it also views design activism as a very important aspect whereby design is not about designing for others only, but also about how one acts as a responsible designer. The role of the designer in the social, cultural, political, environmental, economic and technological fields is emphasised. The way in which a designer participates in this complex system to make a constructive and responsible contribution to local and global visual communication and society as a whole is given priority. The Department of Visual Arts and the Visual Communication Design course encourage situations and class environments for critical thinking and critical discussions, and encourage students to take control of their own learning process and growth. 
Creating such learning spaces was particularly relevant in the case of the Critical Citizenship module, as its details are inherently tied with the general ideas underlying critical citizenship education, as discussed earlier. It is crucial to note that describing all the details and nuances of such a module is not possible, as the concepts dealt with are relational and dynamic, and facilitating such a project entails much more than discussing its brief - it also lies in the tone of voice when a brief is discussed, body language and the way one interacts with students.

The Critical Citizenship module consists of a range of graphic design projects that combined community engagement with critical thinking, reflection and practical visual communication design. The main aim of the module is to focus on changing perceptions and attitudes to enhance personal transformation on a deep level, and ultimately contribute to societal transformation. Other outcomes also mentioned in the general course guide for Visual Communication Design students were, for example, to gain an understanding of the unique role of the designer within the broad cultural and economic context of southern African society, as well as an understanding of the students' own roles as designers; to achieve competence in the development of research skills; and to acquire the ability to act and think critically and innovatively. Specific learning outcomes include, for instance, an advanced practical understanding of the social and cultural role of a designer, interpreting written language into visual language using typography (to also create images) and finding an appropriate visual solution through lateral thinking and visual problem solving.

The Critical Citizenship module was implemented in the Visual Communication Design curriculum in 2010 . The aims of this module include promoting discussions on issues such as power relations, stereotyping blackness and whiteness, and to include some silenced or hidden aspects sprouting from South Africa's divided past that may surface in discussions and practical projects. It also aims at personal transformation that would ultimately contribute to social change. The module further encourages critical reflection on the injustices of the past to enable imagining a different future.

This section has provided some details of the broader context within which the Critical Citizenship case study was situated. It has also demonstrated the inherent complexity of the case, which necessarily influenced the details of the research methodology and process. The next section elaborates on how the research process evolved. 


\section{RESEARCH PROCESS}

Against this backdrop, the case study explored how the perceptions and attitudes of university arts students, school learners and arts lecturers were influenced by introducing critical citizenship education into the curriculum. Critical citizenship education, in this case, involved four particular graphic design projects for Visual Communication Design students, incorporating community engagement and service learning. Students worked in collaboration with Grade 11 high school learners involved with the non-governmental organisation (NGO) VisionAfrika in Kayamandi, an informal settlement in the university town of Stellenbosch. Each of the four projects included theoretical, interactional, practical as well as reflective components. Written reflections formed an integral part of the process. Students and high school learners were required to reflect on their experiences after the first community engagement learning session and also at the end of the project. Through these reflections it was possible to generate data with the aim to understand the changes that took place within students regarding their perceptions and attitudes towards the Critical Citizenship module. Structural reflection writing was applied (Eyler 2002) and an affective-cognitive model of learning (Du Plessis \& Smith-Tolken 2009), which describes emotions within a theoretical context, was used.

An inductive approach, using action learning and action research (ALAR) methodology (Zuber-Skerritt 2001), was applied to the research process, as this relates well to exploring physical and emotional involvement in university-community interactions. Our main assumption in this case was that learning takes place as a result of action or concrete experience, and action is taken because of learning. The ALAR method also recognises that human beings, communities and organisations are difficult to predict; their characteristics, ideas, strategies and behaviours are complex. The aim was therefore not to arrive at generalisations, but to understand, improve or change a particular social situation to the benefit of all participants.

Inductive qualitative content analysis was used in processing and organising data into emerging themes, where no theoretical framework was applied to the data. Research and data credibility was enhanced through triangulation, whereby data were collected from arts students and high school learners who expressed different cognitive and emotional states during their participation in the Critical Citizenship module. Thick descriptions (Lincoln \& Guba 1985) and thorough analysis of the reflective writings from students, the high school learners and lecturers in the module enhanced data trustworthiness.

The details of the four graphic design projects in the module involved the following: 


\section{The profile of participants in the four projects}

A group of six black students, nine coloured students, one Indian student, 81 white students, 32 black high school learners and one white female lecturer, besides the primary researcher (also a white woman) participated in the study. The students were not specifically selected, because they consisted of the first- to third-year Visual Communication Design students of 2010 and 2011 . Each year group consisted of between 23 and 26 students. The learners were also not specifically selected, as it was the group that the community organisation, VisionAfrika, selected from Grade 11 learners in Kayamandi High School. The projects were incorporated into the Visual Communication Design curriculum and the students and learners did not have a choice to participate in the projects. However, in the consent forms that students and learners signed in the beginning of the year, it was stated that they could at any stage withdraw their projects or reflections from the research. Even though the students often discussed their emotions regarding the projects with us, there were no students who withdrew their work at any stage. Data were collected through 193 reflections written by students and 54 written by learners, 11 individual interviews, six group interviews with 98 students and 32 school learners, and one individual interview and written report from the arts lecturer. Reflections of the primary researcher participating in the Critical Citizenship project were also included.

We specifically chose the community interactions between university students and Kayamandi High School learners because most students at the Department and university are white (for instance, in this case 81 were white students compared to 16 black, coloured and Indian students). The Kayamandi learners were from an economically poor area, while most white and some coloured students were from economically advantaged environments and not from Kayamandi, which is only a few kilometres away from where they live. In a university town like Stellenbosch, physical, economic and psychological segregation between racial groups are still prevalent even after 20 years of democracy. Therefore, there was and still remains a need to interrupt the strong stereotypes and even fears that exist in Stellenbosch communities.

\section{PROJECT 1}

The first project, for second-year Visual Communication Design students, was originally called "Mapping Kayamandi", but the students renamed it "See Kayamandi - See Yourself". The project started with a reading of the Giddens (1999) lectures titled "Runaway world: How globalization is reshaping our lives", which discusses issues such as globalisation, risk, tradition, family and democracy. Each paired student 
and high school learner then had to identify relevant social issues in Kayamandi and relate it to theory.

Each second-year arts student had to design five pages that would be bound together in one book. ${ }^{2}$ Page 1 had to describe the social issue that was decided on; page 2 had to use a schema in the form of mapping, modelling, timelines, graphs and diagrams to visually illustrate the chosen issue; page 3 had to present the student's own abstract visual interpretation of the chosen issue; page 4 had to include the student's reflection on the project and interaction in Kayamandi; and page 5 had to consist of a drawing done by the student during the walk-about in Kayamandi, related to the chosen topic. Examples of topics given to students and learners were mapping foot paths, customs, garbage, trees, electric lines, water taps/points, soil types, houses, household listings, cars and parking, road/street names, land occupation, religious/spiritual groups/places, technology, education levels, children or population or timelines of change, chronological record of events/fire, migration or history. The size of the book was specified as $300 \times 420 \mathrm{~mm}$, printed in one colour and on recycled paper.

As mentioned before, the students wrote a reflection after their first visit to Kayamandi as well as at the end of the project. It had to comprise between 600 and 700 words in which they had to discuss their own experiences and emotions, but also had to refer to the Giddens (1999) reading and their own references. These reflections, together with interviews with school learners and observations, were used as research data (see examples of the work done by students in this project in Annexure A).

\section{PROJECT 2}

Project 2 involved third-year Visual Communication Design students in interaction with high school learners identified by the VisionAfrika community organisation. It was based on the question of what skill students would need most to survive in Kayamandi. They had to find out more about life in Kayamandi and, in Nussbaum's terms, "put themselves in the shoes of others" (see Nussbaum's discussion on narrative imagination, 2002). The students started by documenting what one day in the life of a high school learner looks like in Kayamandi, and then they had to decide, together with the learners, what the most valuable skill would be to survive in this informal settlement. Some of the skills differed from what one would need in central Stellenbosch, but there were also many similarities. Examples of skills identified were the importance of eye contact, frankness and social networks. The

2 The book See Kayamandi - See Yourself was published by Sun Press, Stellenbosch, in 2012. 
reading that went with this project was from Jansen's Black dean: Race, reconciliation, and the emotions of deanship (2005) and references to his book Knowledge in the blood: Confronting race and the apartheid past (2009a). A guest lecturer from the Department of Psychology at SU was invited to facilitate the discussion of the readings and create a space for the students to reflect on sensitive issues without feeling that the person who would give them marks (the researcher) might discriminate against them because of what they said. The results of the conversations were compiled in a collaborative book. ${ }^{3}$ The students decided to call the book Action Research Learning Life Skills in Kayamandi (see examples of the work from this project in Annexure B).

\section{PROJECT 3}

This project was based on design elements and principles and involved first-year Visual Communication Design students. These students and the Kayamandi high school learners had to link elements and principles of art (line, space, shape, texture, size and balance, emphasis, unity and rhythm) to a social issue in the participants' own world. Line could, for instance, relate to racial or economic divisions, and space could refer to the mental or physical space of a society. The elements and principles related to their own lives were then acted out in a theatre play. Drawings of the acts, a typographic collage or photos of the acts were then used to explain the concepts visually. The theatre play (five to eight minutes) highlighted an issue or posited a possible solution for the issue.

It was suggested to take into consideration the space and the furniture in the studio (in the Department) and to think of how these elements could be used in helping to express their messages. During the next interaction they used the principles of design, such as balance, emphasis, unity and rhythm, and connected these with a social issue to compose a song. They also had to write an 800 word summary about the issue, and decide on a heading and subheading to use for a final page layout. The project resulted in 12 small one-day exercises and a final A3-page layout (see examples of the work done in this project in Annexure C).

\section{PROJECT 4}

The fourth project was undertaken with third-year students at the beginning of 2011 . These were the same students who had participated in Project 1. This project was called "Design as healing". The aim of the project was to explore the idea of

3 The book Action Research - Learning Life Skills in Kayamandi was published by Sun Press, Stellenbosch, in 2012. 
design therapy (as in art therapy) to assist students and learners to use design as a medium to express themselves and assist them in dealing with issues in their lives. The students were originally hesitant to share distressing moments they have had with one another, therefore the project was adapted so that they did not have to share such moments. They simply used the design process as a medium to deal with their emotions. A guest lecturer from the Department of Educational Psychology at SU facilitated the interactions by using music and working with clay and string to express emotion. The project resulted in a collaborative book for which each student designed five pages of text and images, while the learners contributed by showing their clay, string and cloth sculptures (see examples of the work from this project in Annexures D and E).

The objectives of this specific case study included to (a) identify the reactions to critical citizenship education of students, learners and lecturers related to teaching and learning; (b) establish what the reactions revealed about the immediate teaching and learning context in which students, learners and lecturers learn and teach; and (c) establish what the reactions revealed about the broader context in which students, learners and lecturers find themselves.

To gain insight into these aims, an interpretive approach to research was used. A researcher who takes an interpretative approach is concerned with investigating the "complexity, authenticity, contextualization, shared subjectivity of the researcher and the researched, and minimization of illusion" (Matveev 2002:62, referring to Fryer 1991). Perspectives, which are normally socially constructed, prove to be valuable in sensitising one to contradictions, interpretations, distortions and biases of the narratives generated (Klein \& Meyers 1999). In an interpretative approach, the researcher aims not to impose previous understandings on new research data, as it enables an improved understanding of the context and qualities of the collected data. This is, of course, extremely difficult to do.

\section{RESEARCH RESULTS}

In a study of this nature, researchers cannot be anything but involved. As has been mentioned before, engaging with a curriculum is full of potential, promise, risk and uncertainty - often because it entails willingness to change and some preparedness to be changed or transformed in the process (see Mcllrath \& MacLabhrainn 2007). In reporting the results of this study, we have deconstructed and reconstructed the world of the students, learners and lecturers involved with the Critical Citizenship module - from our own perspective, but, importantly, with an awareness that reconstructing a "reality" could be different from those of the participants' or any other reality; also with the possibility of being personally transformed in the process. 
The reported reflections focus here mainly on the reactions of the students and learners. The five most prominent themes that emerged from the data are discussed under the following headings: (1) Not being prepared for the experience; (2) Experiencing guilt and shame; (3) Resistance to change; (4) Asymmetry and assimilation; and (5) Hope for the future. Other emotional responses are, however, also interweaved in the main themes, as the different themes often interrelate and may partially overlap in some areas.

\section{Not being prepared for the experience}

The word "prepare" comes from the Latin praeparare: prae-/pre- + parare is to procure or obtain, acquire or secure something (Merriam-Webster 2012). To be unprepared would therefore be to feel insecure, ill-equipped or unready. In this section, we discuss the participants' emotions regarding their preparedness for dealing with critical citizenship education. Categories that were prominent include students feeling like foreigners, experiencing discomfort or being out of their comfort zone, fearing the unknown, intruding into personal boundaries, and not feeling psychologically and academically prepared for the content of the Critical Citizenship module.

The reactions of different students and learners regarding critical citizenship education varied drastically. We know that emotions are not only constructed internally and psychologically (on a micro level), but also on a structural cultural (macro) level (Thoits 1989:319; also see our discussion on elements of learning theory in Chapter 4). The contexts in which students, learners and lecturers find themselves, as well as the backgrounds from which they come, contribute in significant ways to constructing their emotions.

As the contexts students were exposed to during community engagement often varied greatly from what they were accustomed to, general feelings of unpreparedness are understandable. Students experienced discomfort: "When I heard that we will be going to Kayamandi I was struggling with mixed emotions. Maybe I still am, maybe I think I am" (Student 3W71). ${ }^{4}$ They felt scared. Student 2W52 questioned whether they could trust lecturers to go into Kayamandi and said, "Were we to leave our student cards behind, just in case? How would we manage to come out again with only our lecturers to guide us?" Students felt psychologically and academically

4 To promote anonymity, the participants are indicated by codes. For instance, 3 indicates that the student was part of the third-year group; W or B means this is a white or black student or learner $(S$ or $L$ ) and 71 means this was student number 71 of the total participant group of 97. 
unprepared and as if they were overstepping personal boundaries by asking learners about their life in Kayamandi.

Two students explained such emotions as follows:

- It was as if we were looking in from the outside, observing and judging their lifestyle, without the adequate knowledge to do so (Student 2W49).

- There was definitely still some awkwardness from my part. This awkwardness was there right from the start of the project. It did not make me feel comfortable when we were told we had to go into this community and use these Vision K students as research material for a project that would not really benefit them in any way (Student 3W76).

The high school learners, on the other hand, did not express much discomfort or feelings of unpreparedness regarding the interactions. To the question whether they felt "used" by supplying information for the benefit of the students, learner BL21 remarked: "The feeling of knowing that you're helping someone was a great feeling. I had a good time with the students. Helping them is helping me". Another learner (BL1) said he felt good "that [he] can help someone, even if [he's] not educated" and BL22 remarked that "it shows that I'm more than I think I am - that other people [students] can learn from me, when I didn't even notice". The learners are used to interactions with people entering their community from the outside, for example various people running the NGO or volunteers from abroad who offer various opportunities to people in Kayamandi as well as find opportunities for themselves to "serve". The students often commented on their surprise at how self-assured and relaxed the learners were. Visiting the university was a new experience for the learners, though, and they clearly felt uncomfortable in the new space, but interacting with the students seemed to be less of a problem for the learners than for the students.

The students also often expressed feelings of being a tourist or foreigner. One student (2W49) said: "It felt as if we were tourists exploring a foreign country on our first touring of the Kayamandi area. I found that the conditions within which they live are so different to my own, although I live a mere 10 kilometres away". There were, however, also students who did not feel like tourists, but experienced a pressing expectation to notice and comment on the possible foreignness of Kayamandi. These were mostly students who came from a similar community themselves. One student (2B6) expressed this as follows:

It was a bit difficult for me to spot things in Kayamandi that some people might find strange, because I grew up in a township. Once in a while I had to try to step outside myself, and view Kayamandi like a tourist 
or someone who grew up in suburbs. I started appreciating the little things about the place like how the people built their shacks, because it shows creativity and it is only they that can build shacks on a small piece of land $[\ldots]$

Most of these experiences probably have their roots in the dualistic mind sets of colonial times which, to varying degrees, still have bearing on the lives of many South Africans today. The knowledge that we have, if not disrupted, could be taken as the "norm", as our ability to change or reflect on our current situation. For Lisle (2010:51, referring to Parker 1997:54) we are extremely vulnerable to "ideology, custom, habit, tradition, coercion, authority and institutionally imposed and maintained expectations". The curiosity and even the fear evoked when visiting a new place can be understood because of the divided past in South Africa and the status quo, which has not changed much. However, it could border on the concept of the "exotic tourist" or the "exotic gaze" (Urry 2001). Fanon (1967) also refers to the "white gaze" and the "fascination with the poor or exotic". If the community engagement remains on the level of fascination, actual reflective learning could be hampered. What we had hoped for is that, after three years of participating in the Critical Citizenship project, the students would be able to go beyond voyeurism and start to interact and communicate unpretentiously and more spontaneously.

The historically biased issues that were triggered in the interactions, created feelings of discomfort for some students, but the interactions were also chosen for that reason. In this regard, the non-researcher lecturer (WLE1) commented that "a certain amount of discomfort is necessary to be aware that the division and inequality we see is deathly and MUST be acknowledged and changed". Being exposed to experiences outside one's own comfort zone could therefore encourage different learning opportunities for most of the students.

The community interactions comprised an actual and active exposure for students, learners and lecturers. If compared to studying in the library, for instance, it produced a completely different emotional response. One student (2W49) said: "It dawned on us as a group that we were not working with a usual source like Google for our research, but with human beings, who have feelings, perceptions, and sensitive histories of their own". This experience was difficult for some students. It certainly awakened an impeding sense of wariness and unease in many. Another student (3W8) expressed this feeling as follows:

I do not think we have the skills quite yet to enter a situation/relationship like the one between us and Vision K, and I think this is where problems arise. For example, we go into Kayamandi assuming to find certain things, therefore approach discussions in a certain manner and somehow often 
end up perpetuating stereotypes and manipulating the truth in order to mould what it is we find to our original assumptions.

It becomes clear that one's reactions are rather different when one reads an article on stereotyping in one's own home or in the library and agrees with all that is said about its damaging effects, from realising in an actual interaction that you are, in fact, stereotyping in that situation. We automatically categorise other people, even if we do not believe in stereotypes, but with different outcomes depending on whether we are aware of the action and whether self-reflection happens when categorising (Devine 1989). This creates discomfort for many, which makes resistance an understandable reaction.

Student 3W8's above comment also demonstrates that the module did not necessarily effect immediate change in the students' perceptions regarding critical citizenship concepts. It might even have made it worse, but it will hopefully be something that they will remember and return to sometime later in their lives. Without this trigger, students may never explore these issues, because one's emotions often remain submerged in the subconscious and are only brought to the surface by a specific trigger. If a trigger brings awareness of something to the conscious mind, it can somehow link with other things that one experiences later and create an opportunity to reflect on it again.

Dewey (1910:13) argued that moments of discomfort often triggers transformative learning and argues that reflective thinking is always troublesome because it engages and involves "overcoming the inertia that inclines one to accept suggestions at their face value; it involves willingness to endure a condition of mental unrest and disturbances". Similarly, Mezirow (1998:185) suggests that meaningful personal and social transformation may result from self-reflection and benefit ethical and moral development. For learning to take place, students, learners and lecturers have to be "deliberate experimenters in their own learning and willingly engag[e] in traumas of the self" (in Fenwick 2001:33). Student 2W56 demonstrated such a critical engagement with his self by reflecting on his experience of leaving his comfort zone in the following way:

This project has caused boundaries to be shifted. I literally moved a boundary by entering Kayamandi. I enlarged my own living space. I also moved psychological boundaries due to the fact that I don't normally, during my everyday life, come into contact with black school children or get to know their lifestyle. The first time we visited Kayamandi was uncomfortable for me, especially working with the children. It was especially difficult for me because to a certain extent I felt ashamed and also sorry for them because my monthly allowance is approximately equal to their parent's monthly income. I was sceptical whether they 
would cooperate with us. I was completely out of my comfort zone. Later I began looking forward to our Kayamandi outings. ${ }^{5}$

What has emerged clearly in this section is that students could be more psychologically and affectively sensitised and better academically equipped and prepared for what they may experience during community engagement sessions. This means that thorough ways of research in such communities should be taught and more effective strategies for sensitising students should be implemented through increased time spent on dialogue and discussions with students.

In Socratic terms, truth is regarded as of great value, and that truth can be realised through reason and logic in discussions. Socratic learning therefore searches for truths "waiting to be discovered, deciphered and interpreted" (Rowe 2005:6). Such increased depth and length of conversations would require lecturers who have patience and are willing to get involved in more sensitive types of conversations while creating a safe and caring space. Apart from such increased conversations, the need to interact with various communities is crucial and, in the context of SU and similar institutions with limited opportunities for exposure, it is even more important for designers to be exposed to differences. Such exposure enables design students to gain capabilities that deal with "real-life, controversial issues" (Kerr 1999:10), and to function in the variety of circumstances a country such as South Africa, but also the world at large, holds.

\section{Experiencing guilt and shame}

In this section, the focus is on feelings of guilt or shame, but also on feelings of being humbled by educational experiences. Guilt in relation to religion and charitable behaviour is also included. We start off with a response from a white third-year student (3W67):

I experienced a lot of guilt throughout the programme, as there seems to be much more suffering in their community than my own. I felt guilty being more privileged than them and conforming to stereotypes which were discussed and which affected these learners negatively.

Feelings of guilt probably surfaced because of the contrasting and unequal contexts that the students, learners and lecturers find themselves in. Guilt in this sense is experienced not because students, learners and lecturers did something wrong, but because they may have felt guilty because of the wrongs of the past committed by their forebears. Their guilt and shame is therefore a product of their reflections; of the realisation of the actions they are hesitant or omitting to take.

5 Translated from Afrikaans. 
Even though the students and learners are of a different generation, the knowledge of the colonial and, specifically, the apartheid past has been transferred through generations. Vestiges of apartheid discourse are embedded in society and continue to have a hegemonic (Gramsci 1971:54) hold on South African citizens. Jansen (2012) argues that university students "have long been socialised into social and educational dogmas". Even though one would expect university students and lecturers to think for themselves and take responsibility, they cannot entirely remove themselves from local contexts that already perpetuate hegemonic power relations. When this realisation occurs, guilt inevitably surfaces.

The social and economic inequality existing between groups facilitates the dominance of a problematic "giving and receiving" paradigm. This paradigm can affirm white superiority because it veils "complicity with racism, homophobia, and other forms of oppression" (Britzman 1995, in Kumashiro 2000:43). Student 2W50 reflected on this tendency when saying she would not, in future, "waltz in there with an inflated saviour mentality, but rather with the intention of sharing: culture knowledge, respect and humanity". Others, such as student 1W45, similarly commented on becoming more aware of their privileged position and being humbled in the process:

I grew up with knowing there are conflicts in the world, however I was [naive] to not realise how close to home these problems truly are. I met [the learner], and she strongly inspired me to become a better person.

Whereas the above mentioned comments of students seem to demonstrate critical awareness of the potential problems of a "giving and receiving" paradigm, other students' comments may imply helping behaviour that can potentially perpetuate unequal power relations and create dependency of one group on another. Student 2W39 wrote:

I'll use the cliché[d] phrase of being humbled, because there is no better way to describe it. To think of the trivialities which my days revolve around in comparison to the issues which they handle with a smile; I realise just how much I have to be grateful for and how important it is that I help improve the issues in less fortunate places in whichever way I can.

It is crucial that helping behaviour is always carefully considered. Bhattacharyya (2004) argues for resisting relationships of dependency when helping; for not assuaging feelings of guilt and shame with charitable behaviour and emphasising the concept of working with and not for communities. Communities should not be moulded into passive receivers, but be allowed space to develop their own agency. This space can be created by developing what Freire (1975) refers to as a "critical consciousness" in students and in communities outside the university. This refers to "not accepting an undesirable condition as fate or unchangeable, [but] understanding the structure of 
causes that brought it about, and then evolving strategies to mitigate them" (Freire 1973, in Bhattacharyya 2004:13).

A certain amount of guilt could therefore be productive in critical citizenship education. It can make one reflect on the past, take critical action to work for a more just society, and so develop agency. Instead of social integration through community engagement remaining an illusion through just providing, according to Biko (2004:23), "vague satisfaction for the guilt-stricken whites", the guilty feelings of students, learners and lecturers should be elaborated on during discussions and then used as a stepping stone to decide what actions to take. Biko (2004:25) urged white people to refrain from solving black people's problems and to concentrate on the evils of white racism in their own personal life and community. He was not suggesting that we should not interact with one another, but that we should leave our superior attitude towards solving other people's problems behind and be prepared to learn. Two student responses regarding helping behaviour illustrate such a critical shift in thinking:

- Helping is a deed, which we need to do, whether it be for religion, self-benefit or from empathy. We just need to question our motives and try to understand others before we glorify ourselves through a[n] honourable act (Student 1W40).

- All of us went in with community workers' or social work mind frames, because, like we were going to do them a favour, but actually we needed a favour from them. It was just the most funny relationship and it was really, really tricky to do (Student 3W71).

The notion of guilt and consequent helping behaviours were often brought in line with issues of faith. One student (3W22) remarked the following when referring to the projects:

I want to make a difference because I am blessed with so much and there are people who have less than I and by not sharing my talents and education and opportunities with them would be selfish. I am also a Christian and I want to help others because I want to share God's love with them. If I can make a difference, why should I not do it? It's about others, not about me. ${ }^{6}$

Helping behaviour and the "giving and receiving" paradigm have roots in religions such as Christianity and Islam. The interactions of the students with learners who mostly were from deprived families and communities might have triggered the feelings of charity in relation to Christian beliefs. In the Critical Citizenship module, religion

6 Translated from Afrikaans. 
and critical citizenship is separated. One can be a critical citizen without necessarily belonging to or associating with any particular religion. One can also be ethical and responsible without adhering to a particular religion. Granados (2009) goes as far as concluding that the moral is not that apartheid was evil; it is that religion heavily influences debate. For many years, apartheid was justified by Christians and the Bible was misused and misinterpreted by so-called "Christian" politicians to fit and promote apartheid ideals. Snyman (2008) remarks that whiteness tends to work through a Christian heritage because it is historically linked to imperialism, conquest and colonialism, which fed racism. The historical sentiment of charity and "chosen people who uplift others" is something from which the Critical Citizenship module wants to distance itself, but having conversations about religion might be a relevant topic in critical citizenship education because values and norms are often interlinked with religious convictions.

Differences in traditions and beliefs also surfaced in the conversations between the students and learners. One student (3W58) wrote:

[The learner] turned to her church and Christianity about a year ago and has a group of friends from her youth group. Although her family is not very religious, [the learner] has become a devout Christian and many of her traditional Mhulbi traditions have been replaced by religious practice. This is a very interesting aspect to look at because one has to wonder what kind of impact the acceptance of another religion has on cultural diversity. Perhaps certain traditional aspects are lost whilst new religious ones are gained and perhaps these new practices will merely became a part of her culture.

She continued:

Another tradition of the Mhlubi is to cut open the flesh near the place of irritation when one is ill. For example, [the learner's] mother had an eye infection and therefore they cut open her cheek. The cut is to let out all the bad spirits.

What are we doing practically with difference - are we accepting each other's differences? Or are we trying to find a place where we can agree on basic values and norms? In the Critical Citizenship module, the concepts of tolerance, diversity, democracy, human rights and social justice are emphasised, but what, for example, does tolerance of diversity imply practically in this case?

Okin (in Gouws 2012) argues that, if a belief discriminates against others, one should criticise or even condemn it. Reconciling religious beliefs with critical thinking becomes problematic. Does one accept varying beliefs as difference, or should one question it critically in the form of research? Becoming aware of these sensitivities in 
critical citizenship education is crucial for lecturers. Separating beliefs from critical citizenship education will not always be possible. This is an area that may require further research within a critical citizenship educational environment.

\section{Resistance to change}

In the context of the case study, resistance refers to concepts such as to oppose and repel and a refusal to accept, or persistence in existing perceptions and attitudes. It was a theme that surfaced throughout, especially when reflecting on the Critical Citizenship module with fourth-year students a year after they had completed the course. Some students were of the opinion that the module opened up issues that were unnecessary to open, because it had not previously been an issue for them. Others felt that concepts such as tolerance, diversity and democracy are ideas that belong in the past and are not relevant, being too aspirational and not possible to achieve.

In the following paragraphs we point to various forms of resistance to change that were experienced by the students and lecturers involved with the Critical Citizenship module. These forms of resistance include resistance to conversations about the past, resistance to particular terminology, feelings of being targeted, resistance to unreachable goals, lack of self-affirmation and resistance to critical thinking. It was obvious that these sub-themes cannot be clearly separated from one another, as the key concepts touched on in each section largely overlap.

South Africa's colonial and apartheid past has created mental contrasts that are often suppressed and silenced (Jansen 2009). In the student reflections, resistance to conversations or projects that involve this past was quite evident to us. For instance, one student (4W57) said:

These projects opened up the racial issues while we were perfectly fine with each other in class [...] before that [...] the older generation should not make their problems ours.

The Critical Citizenship module, and specifically the community engagement, aimed to break this silence and obtain more perspectives on the critical issues involved. Perceptions are socially constructed, pre-existing (Trope \& Gaunt 2003:191), and mostly deeply ingrained. They are often experienced as the norm. Giddens (1984) argues that we have a consciousness that we can talk about (discursive), as well as a consciousness that is hidden and not verbalised (practical consciousness). This hidden information could also be suppressed information; hidden because of fear of the accompanying emotions. These issues could lead to volatile situations. The 
psychological dangers of silencing emotions such as anger, guilt, hatred or hurt could affect one's everyday actions, and therefore also one's learning.

Learning does not only take place through experience. For instance, one could learn from parents without ever having had the experience. Jansen (2009:171) argues that knowledge is habitual and embedded, and transmitted to the next generation. Normally, these ingrained perceptions and attitudes do not play out strongly in theory, but more so in practice. If, for example, one thinks about racism in a theoretical sense, one might agree completely that it is wrong, but when one works with students who are perceived as being disadvantaged, one might often find oneself wanting to give these students extra time. This is an automatic bodily, and not an intellectual, reaction. Sometimes racism "achieves part of its power through being inscribed deeply in individual psychology" (Frosh 1989:210). This type of "subtle" racial discrimination could cause a student to perform or not (Ratele \& Duncan 2007). Such ingrained, bodily reactions need to be addressed psychologically.

Discussing issues in interaction involves a person cognitively and emotionally. Theoretical learning in combination with bodily learning could therefore create optimal opportunities for deep and reflective learning. Because of the experiential learning experience, the emotions - and resistance - accompanied by the actions could be stronger. A cognitive approach to learning leads towards simplification, but a reflective approach "leads towards complicatedness" (Kayes 2002:5-6). Assessing a group of students' emotional state of mind is crucial in order to avoid overstepping the students' ability to absorb information and create barriers. According to the reflections written by the students, the conversations during the community interactions were disruptive. There are, however, levels of disruption and deciding when something is disruptive enough to make a difference is difficult to estimate. Fourie (1999:277) calls for "cognitive transcendence", but we believe a bodily experience is more likely to trigger changes in perceptions and attitudes.

Terms such as "tolerance" triggered resistance, because some students felt that, even though it is a principle practised by all people, such terminology belonged to the past and to when one does community engagement with previously disadvantaged people. One student (4W76) observed as follows:

With all those glamorous words [...] those terms [...] such as tolerance, human rights [...] that is townships. That is my association. That is where you would go and deal with terms like that. You would not go into a big business or [...] I don't know, some other situation. You would go to [the] previously disadvantaged and that is the sort of projects that we do. 
Some students saw the terms as empty and unattainable. In a certain sense, the students are right; social structures such as capitalism and democracy do not necessarily encourage tolerance and human rights. Capitalism is seen by many as promoting the rich getting richer and the poor poorer (Piketty 2014), and even though, for example, everyone has the right to vote in a (seemingly) equal democratic system, individuals have very little power to change social structures. Lock (2007) refers to the philosopher Jean Jacques Rousseau who had argued that we only have power at the moment we vote. After we have drawn our crosses, we simply go back to being slaves of a social system that is almost impossible to change because of the (non-)representative government system. These social structures can cause resistance and might influence students in feeling that terms such as tolerance, diversity, human rights and democracy are empty. The role of academic institutions, lecturers and students is to critically reflect and act on such perceptions and emotions. The difficult part of critical reflection, and the part that causes most resistance, however, is what to do when one consequently realises that one has an ability to change.

Resistance to feeling targeted, to unreachable goals, and to a lack of self-affirmation was often expressed by the participants in our study. People do not want to be reminded that they might be lacking in some skills, or should develop a capability that allows them to change. It makes them feel as if expectations are unfairly high and geared towards targeting their possible personal weaknesses. In one student's (4W76) opinion,

They [terms such as tolerance and diversity] are all very important things. But giving them that [...] It's like putting them on a bit of a pedestal and it is making them [...] it is sort of putting them at a level where we can't reach them by saying this is what we need to be one day, but what are we now? Are we the opposite of all these terms?

Festinger's (1957) cognitive dissonance theory holds that one constantly seeks stability among one's beliefs, attitudes and behaviours, and will therefore resist changes in perceptions and attitudes. Dissonance could be eliminated by reducing the significance of the "incompatible" belief, by obtaining new beliefs as replacement, or by ignoring the "incompatible" belief, attitude or behaviour. Acknowledgement of prejudice might be a compromising activity for those in positions of authority, such as lecturers. Britzman (1998, in Kumashiro 2000:43) suggests that we subconsciously desire learning that confirms what we now already know. We might also subconsciously wish to learn only what confirms that we are good people, and that we resist learning anything that reveals our "complicity with racism, homophobia, and other forms of oppression". This refers to what another student (4W71) said: 
[...] we need to be given some sort of positive feedback that we are not all these ignorant, intolerant, awful people, which is what we have been bombarded with for the last 17 years.

Some students focused more on the terms "critical" or "critical thinking":

[...] we should just strip down to just a simple thing. Instead of like, trying, like to going for tolerance, democracy all that [...] You should just start with critical thinking. Just start with something that just like [...] from that will flow in some direction. But you can't start with all these key words in front of you and try to reach that, because it is so unattainable to see it like that. And it's [...] you just feel drained because you don't [...] you just feel like you're never going to get to that goal. Just start with like step by step [...] ja, simple steps, small victories.

(Student 4W80)

A critical consciousness includes not only learning about the historical and current developments of "privileging/normalising" and "marginalising/othering", but also unlearning what one had "previously learned is "normal' and normative" (Britzman 1998, in Kumashiro 2000:36-37). It should involve a combination of reflecting as well as action. Some students did however express resistance to the "doing" part of critical thinking.

One student (3W73) also remarked that critical thinking is a mere "theory thing" and indicated that linking theory to practice was problematic for her. Critical theory looks at what is taken as the norm and for granted, but it also needs to be incorporated into everyday life. Critical thinking and participatory problem solving cannot be learned without actual experiences and opportunities to practise (Bickmore 2001:59-160). The one arts lecturer (WLE1) corroborated by saying that, even though the Department of Visual Art offers "excellent, critical courses [...] which emphasise the injustices of the past through colonial and apartheid history, [...] students struggle significantly to relate this knowledge to their own context and do not have the tools to imagine a different future, in which their lives are not as insular as [those of] their predecessors".

In opposition to the argument for guarding against resistance, it can be said that the danger of not addressing sensitive issues in society could be just as great. The psychological dangers of suppressing emotions such as hurt, guilt or anger could manifest in destructive actions such as xenophobic attacks and violence - things that have happened frequently in South Africa. Including critical citizenship in educational curricula is therefore of the utmost importance, not only in the social sciences, but in all programmes of learning. A safe environment is needed to unearth and face historical and current realities, one that acknowledges all students' previous 


\section{ENGAGING HIGHER EDUCATION CURRICULA}

experiences and sensitivities. We argue that, by facing sensitive issues and dealing with them thoroughly and consciously, the emotional state of all involved - lecturers, students and learners (and ultimately a society, collectively) - could be enhanced and transformed.

\section{Asymmetry and assimilation}

In the context of arts education, when speaking of asymmetry and assimilation, one is clearly concerned with issues of measuring sameness and difference, of acceptance or denial of difference, of being inside or out. For instance, stereotyping was a central topic raised by the participants in this study relating to these ideas.

Stereotyping is a subjective way of looking at people, and it surfaced in the data from both the students and the learners. One student (3W53) reflected on this by diarising the following:

Being from a white community I can honestly say that my perception of the black community was shaped by stereotypes communicated to me from every angle of growing up - family, school, the media and from personal experience. Although one is able to look past stereotypes for a period of time, our subconscious will always direct you back to what you have believed to be true for most of your life, such as the ideals which have been set forth by your parents. South Africa's history, specifically apartheid, still has the power to sustain stereotypes which were created a long time ago. When one reflects on these stereotypes it becomes clear how absurd they are. As a result of my upbringing I will never be able to live without stereotypes altogether. One could also argue that stereotypes are necessary in a situation where you sense danger as a result of a stereotype you conform to.

Another student (1W45), relating to a high school learner's perception of stereotyping, reported:

I had a conversation with a 17-year-old girl from Kayamandi and found some shocking statements about stereotyping can really hurt other people's feelings and break them down psychologically, especially when it is not true. This girl, [learner's name], says that because the people in Kayamandi are black, they cannot go to the area opposite them as those people are coloured and do not accept the black people from Kayamandi purely because of their race. Therefore the people from Kayamandi hurt or even kill the trespassers from the other area because they dislike them for basically no valid reason. This resulted in a type of "feud" between the black people in Kayamandi and the coloured people from the other area, just because they stereotype each other. 
The polarisation of groups as either similar or different creates a dualism, and this can be problematic. Even though a dualist perception simplifies and places things into neat categories, grey areas, in reality, exist in between. The moment that we feel we know the other, we also feel that we can control the other. Constantly remaining aware of the complexity and the various grey areas in-between would result in not fully knowing, or feeling the urge to control the other. Derrida argues that binary oppositions as woman $=$ weak versus man $=$ strong are maintained because it keeps power relations intact (in Sim \& Van Loon 2005:90). Erasmus (2009:49) argues that binary relations should be addressed, as a transformed campus will be one that can "embrace and promote change in terms of the social and symbolic organisation of academic and social networks and relationships, and [...] do away with stereotyping dualisms".

The obvious unequal hierarchies in the Critical Citizenship module were the facilitator-student-learner relationships that included age differences, educational qualifications and/or life experience. The hierarchies between lecturers and students already prove to be problematic with regard to creating a space for open and honest conversations where sensitive issues can be tabled. If the difference in hierarchies of the students and learners are too substantial, one could wonder whether there would be any chance of real reflection on the learners' side to, for instance, stand up against the "inferior" position that is imposed on them by some students. Obviously school learners have to be consciously prepared to handle such unequal relationships.

Unequal power relations could give rise to persons or groups assimilating and amalgamating. Assimilation could take place between the student and learners, but also between the students in the class. The students learned in and shared a classroom that consisted of a multicultural group of students, but certain groups dominated because there were more of them, but also because of dominating Western cultural media influences. Newman (in Grant \& Sleeter 1994:177) refers to various theories of multiculturalism concerning groups that become assimilated and amalgamated (also see our discussion of the "multicultural curriculum" in Chapter 4).

The current situation in the Visual Communication Design programme, where black students are in the minority, strongly reflects Newman's theory of assimilation, by which the minority is dominated by the majority. Any attempts to change this into an amalgamation model of plurality will be problematic, because of the complexities of status established by political and historical systems of the past. The classical cultural pluralism theory emphasises that cultural groups maintain their identities and modified cultural pluralism develops it further by stating that cultural diversity will continue to occur in spite of efforts to assimilate or amalgamate. A milieu that 
could be conducive to creativity, and where the various cultural groups would maintain their uniqueness while integrating on an equal basis, seems to be possible with the classical and modified cultural pluralism as explained by Newman (in Grant \& Sleeter 1994:176).

Opening up racially-related issues as discussion points emphasises difference and could possibly "other" students. One student (4C1), for example, felt that the researcher "othered" her by encouraging her to use her Muslim culture as inspiration for her designs. She also commented that "[she] felt that [she] had to give up [her] scarf in res[idence] because [she] did not feel comfortable wearing it", and that "[i]t appears to [her] that the white cultures want to force their culture and way of life on the minority on campus". This student also mentioned that she wanted to do what other students did, and preferred not to be different. The impression was created that, because the dominant group was so strong, it would be difficult for a single Muslim student not to conform. This student also indicated that she wanted to show that she could do what others did before using her own culture as inspiration.

In combination with the uneasiness of students losing aspects of their own culture, there is also the anxiety of not being competent according to the expectations of the dominant Western world in the class situation. One realises that students value their own culture strongly, but are somewhat hesitant to apply it in the class situation. Some students prefer not to be singled out, and rather assimilate. Jones (2006:41) describes this phenomenon as a "double invisibility" process, whereby students themselves do not want to stand out from their peers, and lecturers "do not wish to see these students as targets of their diversity efforts". They therefore act as if everyone is the same. Kumashiro (2000) refers to the dangers of the assimilationist theory, whereby students of colour conform to mainstream culture. Kumashiro (2000:28) comments that "educators need not only to acknowledge the diversity among their students, but also to embrace these differences and to treat their students as raced, gendered, sexualized, and classed individuals". Lecturers need to make it clear in the classroom through discussions that diversity in race, gender, sex and class are all recognised as legitimate and also welcomed. Students can also be encouraged to explore their own race, gender, sex and class in projects and afterwards the outcomes of the projects can be discussed with a facilitator that ensures that diversity is recognised and embraced.

Intolerance of one another in a class or community engagement situation could cause psychological damage, especially if the majority overpowers the minority and the minority conforms to certain norms. In this situation, students who conform may also start to question their own norms and values, which could influence self- 
esteem and ultimately affect learning. In the colonial and apartheid past, white and Western were considered superior, even though they were not in the majority. The psychological scars that black, coloured and Indian students and learners may be carrying with them because of the unequal past, together with a class situation in which white, Westernised individuals form a majority, provide a demanding twofold environment to succeed in. Against this background, one black student (2B6) expressed conflicting emotions:

Maybe they [the learners] are going to think I am one of those rich spoilt kids (cheese boy coconut). I know people from the townships do not really like those kids. So I had to show them that I can also speak Xhosa and "tsotsi taal" (gangster language). You can tell someone is from the township by the hand shake and also by the whistle. Since I am from the township, I knew and understood why the Kayamandi people do certain things. I even spoke Xhosa with my partner [the learner], because I wanted her to feel comfortable. It was weird when I was asking certain questions. I thought she was going to think I am acting like I do not know those things.

A psychological battle developed in the minds of the colonised because the meaning of white was attached to what is good (Ratele \& Duncan 2007:127). Traces of these types of psychological scars are still found among students and learners today. Another black student (4B5) "learned to tell herself that these things should not bother her [...] my skin has become thick". Still, a response from one other black male student (2B3) indicates that "it felt like people were staring at me. I felt the same way at the Information Technology Centre and I could not concentrate". This confirms that his learning was affected by his environment. The visit to Kayamandi affected this student (2B3) emotionally. He said, "I felt like I was stuck between two worlds", and the interaction with learners reminded him that "to know where you are going you have to know where you come from". The feelings of doubting himself and searching for an identity to hold on to are evident in this student's reflections.

Students coming from an environment that is hugely different from what they experience in class or on campus unavoidably have to develop a capacity to adapt. Adapting in various environments could also be a positive learning experience this is if the student emotionally survives the experience. Kumashiro (2000:27), however, argues that, despite the apparent differences between black students who "'succeed' and those who 'fail' or simply fail to distinguish themselves, all experience oppression".

Another student (4B2) further added that "Stellenbosch will either break you or make you". This situation could create students that become psychologically numb or rebel 
against their circumstances. From this vantage point, Foucault (1998:136) warns that people could start to regulate their behaviour to conform to pre-established norms. A person can be "trained" and "disciplined" to produce a disposition that may be "subjected, used, transformed and improved". This regulated behaviour then becomes the norm. Despite the power of the individual to contest such power domination, resist stereotypes and refuse to accept social conceptions, it is in the interest of a dominant group to keep social hierarchies in place (Ratele \& Duncan 2007). A student in this situation will most probably experience feelings of frustration, which could affect her or his learning.

In the SU context, psychological and self-confidence problems might be the single biggest obstruction to learning, apart from language barriers. Creating a space for students, learners and lecturers in the Critical Citizenship module to talk, write and artistically explore their personal experiences could be a means of reflecting and coming to terms with emotions, and create a path for enhancing self-esteem. Rhoads (2000:41) argues that we should help students to develop a healthy sense of self if we want students to adopt active roles based on tolerance and empathy for others in society. A caring educational environment is therefore vital (Rhoads 2000).

\section{Hope for the future}

This identified theme focuses the research results on students and learners who commented on useful aspects of the Critical Citizenship module and on how the module motivated them to reflect on their lives. Such positive comments were encouraging. Some students found it to be a life-changing experience that broadened their horizons; an experience that developed critical thinking and that made them come to feel empathy and respect:

It was after these meetings that I changed my outlook on life. I realised that we lived in a country that had faults, and that South Africa was still recovering from the awful period of apartheid. But it was also evident that there was a desire to overcome these hardships and aspire to a future where everyone was equal. I therefore walk away from this experience with a renewed understanding of my position in society as a white person, and a profound respect for those less fortunate than I am. Thus, my feelings regarding this project are now feelings of deep appreciation and respect, and no longer fear and uncertainty.

(Student 1W46)

The experiences students had in the Critical Citizenship module also seem to have made them aware of their own ignorance, naivety, subtle discrimination and the importance of breaking down barriers. One student's self-reflection diary read: 
The experience overall helps one to move outside the usual environment and step from one's safety net and make yourself approachable to these young strangers. It forced us to think outside the box and in a way place ourselves in their shoes, if only for the hour we were with them. ${ }^{7}$ It was a process that taught us to do thorough research and to keep on thinking and rethinking, with the goal to dissect and digest the various opinions of the students, as well as the more theoretical information we were exposed to.

(Student 3W70)

Some high school learners commented that, for them, the projects were about building relationships, improving multicultural communication and gaining respect for each other's culture. The main [aim] of the project was for the students to know the people of Kayamandi, have a better relationship with them and to improve their multicultural communication skills.

These aspects, although not explicitly, say something about tolerance, diversity, human rights and democracy and may involve the first steps towards shifting perceptions and attitudes. However, despite the positive reactions of some students, one remains hesitant about whether the actual aims of changing perceptions and attitudes were achieved. One student (2W54), for instance, correctly remarked that "unfortunately we also fall victim to our own human nature which is to see, to sympathise, to leave and to forget". It seems that the Critical Citizenship module made an impression on most students, positive and negative, but one can argue that the change, as the student remarked, may be of short duration.

Hardt (2008) argues that society can only change if behaviour that reflects "normal" human nature can be changed. Because of the nature of evolution, we are competitive and selfish creatures who are firstly interested in our own future existence and will accommodate the other only when others can add to our own future. This response is very much the reaction of the primitive brain (brain stem and the amygdala) that reacts immediately and spontaneously (Stein in Jarvis 2006). The neocortex, where thinking occurs, has developed more prominently in humans. It is the part that can reflect and be conscious of the self and of others. We are not only thinking beings, we are also feeling and acting beings (Jarvis 2006:14). Research by Trivers (1991,

7 All projects were different: most projects were two or three weeks long. Some started with an hour of students and learners getting to know each other, for instance playing or doing a walkabout in Kayamandi and/or central Stellenbosch. The next day the interaction of the previous day and the readings were discussed in a two-hour session. Usually two or three days after, a follow-up session of two hours took place. The results of the projects were then exhibited and discussed on the last day of the two-week project. All projects had at least three interactions of two to three hours each. 
2011 ) shows that evolution has rendered our brains more suited to "self-deception" than critical thinking. One would protect one's own views in order to survive by, for instance, not accepting other's views even if they are proven to be beneficial to everyone's survival. One may be able to reflect critically on an issue and even agree that it is appropriate, but nevertheless resist the change emotionally. Longer-term changing of perceptions and attitudes through the Critical Citizenship module is therefore not certain.

We therefore conclude that developing critical thinking in students is of limited use if their emotional reactions are not understood. Nussbaum (2011) remarks that developing an emotional capability is crucially important and therefore one cannot assume that students, learners and lecturers are emotionally mature enough to bypass emotional attachments to enable them to think critically. Spaces for debriefing (Boud \& Knight 1994) and dealing with emotional issues therefore seem crucial in any future developments of the Critical Citizenship module. In a South African context, focusing on emotional growth may also help social transformation to move forward.

What this piece of research has shown is that art and design can effectively be used as a medium to facilitate emotional growth and social transformation. The artmaking process, most explicitly in Project 4, became an emotional space in which the students could explore their own feelings of discomfort, guilt or resistance. The students explored personal issues on a deep level that allowed for self-discovery. For instance, one student (3W56) commented on her learning experience in the following way:

It gave me a means for expressing emotions that I was unable to identify otherwise, perhaps because I never really wanted to. The setup also was safe for scratching around in very personal themes, because no one would understand what you were doing. It was abstract, but so powerful. I wrestled with my clay until I felt that everything bad was trapped within it. I was excited, even though we were engaging deep, uncomfortable themes. I was happy, finally to have found a way of dealing with the bad things without exposing my soul. I was glad that I no longer had to bear the suffering of years on my shoulders. The uncomplicated process of working in clay released me from heavy baggage. This also means that one no longer has to fear what may happen in the future, because you now know how to concert bad situations into a learning process. ${ }^{8}$

On the basis of the Critical Citizenship module case study we are convinced that, even though conversations with others are important, reflecting silently (such as in the "Design as healing" project) is also valuable. Foucault (1998) emphasises the

8 Translated from Afrikaans. 
importance of silence in forcing inner conversations, which is conducive to selfreflection. Wesley (2007:13) maintains that art could produce a unique "sacred learning space" that could be advantageous to emotional growth and "create multiple ways of learning and knowing". Buchanan (1998:65) also urges art and design students to present their problems as well as their successes, as art and design is an ideal vehicle for the development of self-discovery.

Through our design teaching and observation of the students' progress, we have noticed the emotional growth that the students experience specifically reflected in their visual work. Because art makes use of metaphors, it works in an indirect way. Art is also an expressive means for coming to terms with the past and with current South African realities in an emotional and non-confrontational manner. Art and design could be used as a "boundary object" (Boyer 1996) that forms the medium through which sensitive issues are opened up and addressed through curricula. On its own, however, the art and design process is not sufficient to address sensitive critical citizenship issues and therefore should be regarded as interrelated with other factors that play a role - this includes content and context.

Apparently, art can be used in educational curricula as a medium for transformation and communication. Evidence for this view emerged when one student (2W62) responded to his changing perceptions of design and art education by observing that "[t]he social responsibility of being a designer is a fact that our course has emphasised to us from the very beginning of the first year of our studies. However, I have always battled to comprehend exactly why it is stressed so much. It was only during this project that I have begun to understand this role".

We therefore need to think beyond art in its strictly disciplined form, as creative thinking and imagination are of crucial importance in all spheres of life and should be developed widely in education and society. Nussbaum (2002:301) argues that one of the central purposes of education is to "cultivate [students'] ability to see complex humanity in places where they are most accustomed to deny it". This kind of skill requires not only theoretical and experiential knowledge, but also the use of imagination. To put oneself in the shoes of others, one needs an empathetic view of others. To really see and feel the suffering of others, one has to have imagination and the world of the arts is a field where these skills can be enhanced.

It is necessary to imagine the unseen, but also to recognise what is really in front of our eyes. We are confined to our constructed social and personal categories and stereotypes. Without the imagination, according to llyenkov (2007), we see what we already know and not what is really there. In art and design, students' imagination is developed and this could also be the reason why the students wrote expressively, 
positively as well as negatively, when reflecting on the Critical Citizenship module. However, imagining a different future would need more than such an act. Just as the word "critical" is added to thinking, "critical" should also be added to reflection and imagination. The aim of critical imagination should therefore be transformative.

Although one realises that changing perceptions and attitudes is not facilitated easily, reading through the comments from the students and learners in the past number of years and analysing the data for this study gives one a feeling of hope that the module has shifted some perceptions and attitudes. However, this hope is should be realistic (Carlson 2005:25), and should thus be constantly and realistically assessed. Zembylas (2007b:xvii) refers to "critical" hope - a "relational construct that is both emotional and critical". The notions of hope and transformation are what emotions are about and it is our emotions that "encompass hope, passion and struggle for a transformed life world that rises above injustice, discrimination and healing of past traumas" (Zembylas 2007b:xvii). The Critical Citizenship module aspired to contribute in a small way to the Stellenbosch University HOPE Project (2010) that aims to make the world a better place - a place that creates hope for the future.

\section{CONCLUSION}

What we have established in this chapter is an exploration of the perceptions and attitudes of students, learners and the lecturer regarding personal transformation through teaching and learning in the Critical Citizenship module in the arts curriculum at Stellenbosch University. This case with its four projects revealed main themes such as students feeling unprepared for this type of project, feelings of guilt and shame, feelings of resistance to change, feelings of asymmetry and assimilation, but also feelings of hope for the future. Other responses from the students, high school learners and lecturer that were interweaved in the main themes suggested feelings such as empathy, privilege, humility, re-evaluation of priorities and values, sameness and difference, feeling out of a comfort zone, and reflecting on blackness and whiteness.

The results from our case study demonstrated that, as students are thinking, feeling and acting beings, it seems important to take the emotional aspects of learning in critical citizenship education well into account. But, moving beyond emotional reactions towards rational actions also seems crucial. The students' reactions in the arts education case generally showed that they experienced the Critical Citizenship module as different from other modules - not only because it involved action research and community interaction, but because they realised that, on a cognitive level, it involved personal involvement and personal change - ideally for the better. 
Our exploration also re-emphasised the importance of strategies such as dialogue, community engagement, reflection and art as mediums for expression in critical citizenship education. It became quite evident that more and longer sessions for student-lecturer-community dialogue need to be facilitated in curricula so that topics for discussion can be explored in greater depth. It also showed that the environment for discussions should create safe curriculum spaces where students can discover new realisations about themselves in relation to society. Critical citizenship should therefore be something that is not so much taught, but personally experienced by all participants in a non-hierarchical fashion.

In the final instance, our research demonstrated that critical citizenship cannot be taught in isolation, because the context in which it plays out is a vital role. An inclusive critical citizenship curriculum within community engagement involving the wider society is therefore suggested. Developing an inclusive curriculum that involves communities external to the university might often seem undoable, but the consequences of excluding communities, especially in a society in flux and democratic development such as in South Africa, could be detrimental. It is important to come to terms emotionally and psychologically with the immediate context in which we teach at South African universities as well as on the African continent before making connections abroad. Higher education could, in this way, make modest but important contributions to more stable societies by including critical citizenship education on a broader scale in university curricula. What this case has clearly demonstrated is that nuance and complexity are involved in critical citizenship education - specifically in an arts curriculum at a post-colonial, post-apartheid and previously white Afrikaans university. In the last chapter we briefly revisit what was highlighted in the previous chapters and touch on the important issue of inclusivity in critical citizenship education. We also propose a conceptual framework that can serve as a basis for both understanding and planning critical citizenship education interventions. Finally, we suggest items for further research into critical citizenship education in higher education curricula. 